\title{
Collecting, Sharing and Utilising Data to Inform Decision- making and Improve Equality
}

\author{
Dominique Allen ${ }^{D}$ Associate Professor, Monash University, Victoria, Australia
}

\begin{abstract}
Although we live in an era in which government and private organisations collect large amounts of data, this has not filtered through to anti-discrimination and equality law in Australia. Government and its agencies have little incentive to collect information, nor does business. Neither group bears any obligation to tackle discrimination if they detect it. Yet the self-regulating enforcement model used in equality law is premised on the idea that information will be available to aid voluntary compliance. This article examines the nature of the data organisations that are currently required to collect and identify significant information gaps. It argues that it is not enough to simply fill those gaps with information; increased data collection needs to be accompanied by the obligation to address inequality if that is what the data reveals.
\end{abstract}

Keywords - equality, data, exceptions, special measures

Disclosure statement: No potential conflict of interest was reported by the author.

License: This work is under Attribution-NonCommercial-ShareAlike 4.0 International (CC BY-NC-SA 4.0)

https://creativecommons.org/licenses/by-nc-sa/4.0/

Suggested citation: Allen, D. (2021). “Collecting, Sharing and Utilising Data to Inform Decision-making and Improve Equality Outcomes" Law in Context, 37 (2): 88-97, DOI: https://doi.org/10.26826/law-in-context.v37i2.152

\section{Summary}

1. Introduction

2. Address Discrimination and Promoting Equality in Australia

2.1 Resolving a Discrimination Complaint

2.2 The Position of Data in the Current Model

2.3 Exceptions Permitting Special Measures

2.4 Actuarial and Statistical Data Based Exceptions-Insurance and Superannuation

3. Equality Data Collecting, Sharing and Reporting

3.1 Employment Data

3.2 Data Collected by the Equality Agencies

4. Utilising Data to Inform Decision-Making and Improve Equality

5. Conclusion

6. References

\section{INTRODUCTION}

We are living in an era in which we are routinely asked to relinquish personal information. Government and private organisations collect large amounts of data about their customers, clients, and employees. Recently 
the proliferation of organisations using QR codes to enable contact tracing during the COVID-19 pandemic has led to them amassing swathes of personal data or outsourcing this to third party providers (Nguyen, 2020).

The growth in the collection of data has not filtered through to the equality space in Australia. The various levels of government and their agencies have little incentive to collect equality related data, nor does business. Neither group bears any obligation to tackle discrimination if they detect it. The prevalence of discrimination remains hidden due to a privatised dispute resolution system and the reluctance - and sometimes the inability - of the equality agencies to collect and release information about the nature of discrimination claims and their resolution.

Individuals bear the responsibility for enforcing equality law. The statutory equal opportunity agencies in each state and territory, along with the Australian $\mathrm{Hu}$ man Rights Commission, are charged with educating the community about discrimination laws and encouraging organisations to comply with their legal obligations. The model relies on organisations to self-regulate and the agency provides them with information about what the law entails and 'best practice' to equip them to do so. The agencies cannot do anything if an organisation fails to comply, such as investigate the organisation. They can only act if an individual victim lodges a complaint in which case the agency's role is to attempt to broker a settlement.

In every jurisdiction except Victoria, the agency must be given the opportunity to resolve a discrimination complaint before the complainant can go to court. The agencies act a 'gatekeeper' to both the dispute resolution process and to information about the nature of discrimination and how it is being addressed.

When they gave the equality agencies this function as a gatekeeper, governments presumably intended that the agencies would gather and use information they collected about complaints to educate and advise complainants, respondents and the broader community about the prevalence of discrimination, its nature and to identify areas of concern to target. Yet partly because they consider themselves to be constrained by the confidentiality clauses regularly included in settlement agreements and statutory privacy requirements (Allen and Blackham 2019), and partly because of the resources involved in gathering and disseminating data, the equality agencies release very little information about the nature of discrimination, its prevalence or causes. It is difficult to discover much about the quantity and quality of information that they hold, even for research purposes (Thornton and Luker 2010).

The self-regulating model used in equality law is premised on the idea that information will be available to aid voluntary compliance but as this article explores, there are significant gaps in data collection and dissemination. Furthermore, collecting data is not enough in and of itself. Collection needs to be accompanied by an obligation to use that information to address the problem, whether that obligation falls on the organisation itself or on the equality agency which could, for example, be granted the power to inquire further into a sector or employer if the data indicates a problem.

This article begins by outlining the model of addressing discrimination in Australia and highlights that in three ways it is premised on information being available. First, the model expects that organisations will know what they need to do to comply with their obligations. To do this, they need access to internal and external information about discrimination and equality. Second, in this model, the equality agency is the gatekeeper to the complaints resolution process and, consequently, it holds masses of information about the nature of discrimination persisting in the community, such as whether an organisation is a 'repeat offender'. Third, legal definitions of discrimination and some exceptions explicitly refer to the existence of particular information which may or may not exist. The second part examines the information about equality that organisations are currently required to collect and identifies the gaps. In particular, it considers the exceptions that permit special measures and permissible exceptions based on actuarial data before examining the data organisations are required to collect. This data solely relates to the employment context. It then considers the equality 
agency's role as a gatekeeper to information, noting that it only deals with complaints which - by their nature relate to when things go wrong, meaning the agency is only the gatekeeper to a particular type of information. As this part notes, there are significant gaps in the data available to inform decision-making and, ultimately, improve equality. The final part of the article argues that although the enforcement system would be stronger if organisations were required to collect data and report on it, this is only part of the solution. The other part is to impose an obligation on an organisation to respond to the information it collects by doing something to address inequality.

\section{ADDRESS DISCRIMINATION AND PROMOTING EQUALITY IN AUSTRALIA}

\subsection{RESOLVING A DISCRIMINATION COMPLAINT}

Laws prohibiting discrimination on a range of attributes in both employment and non-employment exist at the Commonwealth level and in each state and territory. ${ }^{1}$ Across the country, the law is enforced in the same way in that it is dependent upon the individual who has experienced discrimination. They do so by lodging a discrimination claim either at the Australian Human Rights Commission or their local statutory equality agency. The agency must have the opportunity to attempt to resolve the claim through a conciliation conference before the individual can proceed to court. ${ }^{2}$ Most claims settle confidentially or are withdrawn; very few reach a public hearing (Allen 2009)

The statutory equality agencies are not enforcement agencies so they cannot prosecute recalcitrant organisations or to pursue claims on behalf of individuals. Their primary functions are to receive and investigate discrimination complaints and to educate the community (including employers, educators and providers of goods and services who have obligations under equality laws) about discrimination and equality.
It has been argued elsewhere that the absence of a regulator which can impose sanctions is a deficiency in the enforcement of equality laws (Smith 2006; Allen 2016). I do not revisit those arguments here. My goal is to examine the current model and consider the role data is expected to play in the enforcement structure which, as this shows, relies heavily on self-regulation and compliance by public and private organisations both in the employment and non-employment contexts.

\subsection{THE POSITION OF DATA IN THE CURRENT MODEL}

The current model rests on the assumption that data is available. It does so in three ways. First, the basis of the model is that organisations will self-regulate. They will collect information about their workplace, educational facility or service and use that to identify any risks to the employees, students or customers and take action to address it, assisted by the guidance material and information provided by the equality agency about what compliance and good practice looks like. Organisations which fail to comply with the law may be subject to a discrimination claim. The model, in this respect, expects organisations to be self-regulating yet they are under no obligation to collect and utilise data; failing to obtain and utilise information as the basis for decisions only becomes an issue if the decision is challenged.

Second, within this framework, the equality agency is positioned as a gatekeeper of information about complaints. In every jurisdiction except Victoria, it is compulsory for claims to be lodged at the local equality commission (or the Australian Human Rights Commission if it is a federal claim) which will investigate the claim and attempt to resolve it through conciliation. The agencies have the power to compel the production of information in the context of trying to resolve a dispute ${ }^{3}$ but there is no publicly available information about how often they exercise that power.

The final way that the model assumes that information exists is through the terminology used in the

\footnotetext{
${ }^{1}$ The Fair Work Act 2009 (Cth) prohibits workplace discrimination but it uses a different model from older, traditional anti-discrimination laws so it is not considered further.

${ }^{2}$ The exception is Victoria where complainants can lodge their claim directly at a civil tribunal: Equal Opportunity Act 2010 (Vic) s 122.

${ }^{3}$ See eg Australian Human Rights Commission Act 1986 (Cth) s 46PI; Equal Opportunity Act 1984 (WA) s 86(1)(b)
} 
statutes. Complainants bear the entire burden of proof so the underlying assumption is that they will be able to access information to prove their claim, such as showing how a hypothetical comparator would be treated in a direct discrimination claim ${ }^{4}$ or showing that a "higher proportion' of people without the attribute in question would not be disadvantaged in some indirect discrimination claims. ${ }^{5}$ The statutes also assume that respondents will have access to information if they rely on an exception to defeat the claim, specifically the special measures exceptions, which permit measures to address an identified inequality, and exceptions that permit discrimination if the respondent relied on actuarial or statistical data and it was reasonable to do so. Because of the role that data plays either explicitly or implicitly in justifying an exception, it is necessary to examine the two types of exceptions in detail.

\subsection{EXCEPTIONS PERMITTING SPECIAL MEASURES}

Anti-discrimination laws contain 'special measures' which permit an attribute to be taken into consideration for the purpose of reducing past disadvantage. For example, an employer might advertise a position for Indigenous applicants. Special measures are used to benefit a group in order to achieve equality or overcome the disadvantage the group has experienced collectively due to a protected attribute such as race, sex and disability. They are temporary, so once the inequality has been addressed, they are considered to be discriminatory and no longer necessary. ${ }^{6}$ The person imposing the special measure has the burden of proving it was a special measure and so these provisions operate as a defence.

In an early case about the new special measures provision in the Equal Opportunity Act 2010 (Vic) ('EOA (Vic)'), the Victorian Civil and Administrative Tribunal issued detailed guidance about how an organization (whether an employer or service provider) should determine whether a proposal constitutes a special measure or not in response to a submission from the Victorian Equal Opportunity and Human Rights Commission ('VEOHRC') (as intervener) that the community would benefit from more information about their operation. In Waite Group VCAT Member Dea, noted that inequality is central to a special measure because "[w]ithout inequality there will be no work for a special measure to do." ([40]) so organisations need to identify inequality and its cause. In doing so, she said, the questions the organisation must ask itself are "How do you know there is the inequality? Are there statistics, studies or reports which explain its nature and cause?".7

Special measures are one of the few instances in which inequality could be addressed proactively because the onus is on the organisation to act and address past disadvantage. However, none of the statutes place an obligation on the person who wants to introduce the special measure to gather information about inequality, which raises the question - without proper information, how can an organisation know whether a special measure is needed? If the organisation was required to collect information in a systematic way, they could use it to develop a special measure and they would have the data to justify such a program and a baseline to use to evaluate its success.

\subsection{ACTUARIAL AND STATISTICAL DATA BASED EXCEP- TIONS - INSURANCE AND SUPERANNUATION}

Every anti-discrimination statute except for the Racial Discrimination Act 1975 (Cth) contains exceptions which make what would otherwise be unlawful conduct lawful. For example, it is permissible to discriminate when hiring some to work in the home, ${ }^{8}$ in the ordination of ministers of religion, ${ }^{9}$ for single sex sport ${ }^{10}$ to name just a few.

\footnotetext{
${ }^{4}$ See eg Equal Opportunity Act 2010 (Vic) s 8.

${ }^{5}$ See eg Anti-Discrimination Act 1991 (Qld) s 11(1)(b).

${ }^{6}$ See eg Equal Opportunity Act 2010 (Vic) s 12; Sex Discrimination Act 1984 (Cth) s 7D.

7 [2016] VCAT 1258, [44].

${ }^{8}$ See eg Discrimination Act 1991 (ACT) s 24.

${ }^{9}$ See eg EOA (Vic) s 82(1).

${ }^{10}$ See eg Sex Discrimination Act 1984 (Cth) s 42.
} 
There are exceptions which permit discrimination in the provision of insurance and superannuation provided the discrimination is based on actuarial or statistical data. The range of attributes the exception covers range from broad 11 to narrow. ${ }^{12}$ If the data is not available or cannot be obtained, then the discrimination is only permissible if it is reasonable in the circumstances (s 47(c)). These exceptions allow insurers to charge consumers different prices according to the level of risk that they pose. The NSW tribunal discussed this in Auto $\&$ General Insurance Company Limited $v$ President, AntiDiscrimination Board:

It is of the nature of insurance that it seeks to match the risk to the price, allowing a margin for the risk-taker, the insurer. Historically, insurers have priced risk by reference to characteristics personal to insureds as a class... In that way people with the 'good risk' characteristics may pay a lower price for cover than those with the 'bad risk' characteristics. ${ }^{13}$

A typical provision is s 47(b) of the EOA(Vic) which provides that an insurer may discriminate by refusing to provide an insurance policy provided the discrimination "(i) is based on actuarial or statistical data on which it is reasonable for the insurer to rely; and (ii) is reasonable having regard to that data and any other relevant factors." In QBE Travel Insurance v Bassanelli Mansfield $J$ considered the equivalent exception in s 46(1)(f) of the Disability Discrimination Act 1994 (Cth) ('DDA'):

It involves an objective judgment about the nature and quality of the actuarial or statistical data relied on. The actuary or statistician (or the data itself) may indicate that for whatever reason it would not be reasonable to rely upon it. It may be qualified, or be an insufficient sample for reliable use, or not be directly applicable to the particular decision... The data may be incomplete, or out-of-date, or discredited, and the decision-maker ought, in the circumstances, to have known that. ${ }^{14}$

There are very few cases about the operation of these exceptions, but they often become, as President O'Connor said in Auto \& General Insurance Company Limited v President, Anti-Discrimination Board, "a contest over actuarial assumptions". ${ }^{15}$

At issue in Ingram $v$ QBE Insurance (Australia) Ltd ('Ingram') ${ }^{16}$ was whether the data existed. Ella Ingram had to cancel a school trip to New York after she developed depression and was advised by psychiatrists not to travel. QBE Insurance denied her claim, relying on a clause in its insurance policy under which it is permitted to refuse coverage when the cancellation is the result of a mental health condition. Ingram developed the condition after she'd paid for the trip so, she said, it was not a pre-existing condition she had to disclose when she obtained the policy. She claimed this was disability discrimination. In defending the claim, QBE Insurance sought to rely on the exceptions in s 47(1)(b) of the EOA (Vic) and the equivalent in s 46(2)(f) of the DDA. The data was central to its defence but QBE Insurance was unable to produce any actuarial or statistical data, other than data prepared in advance of the hearing which was not available to QBE Insurance when it refused Ingram's claim. ${ }^{17}$ Thus, it could not rely on either exception because, Member Dea said, it did not produce "evidence to establish that the statistical data relied upon was in existence when the terms of the policy were formulated or that any person involved in the drafting or approval of the policy wording had any knowledge of or regard to those statistics". 18

Ingram was the catalyst for the VEOHRC launching an investigation into whether travel insurers were

\footnotetext{
${ }^{11}$ See EOA (Vic) s 47 which extends to all attributes in insurance.

${ }^{12}$ Eg in NSW the exception only covers sex, disability and age: Anti-Discrimination Act 1977 (NSW) ss 37, 49Q, s 49ZYT.

13 (2010) NSWADT 229, [34].

14 [2004] FCA 396 [30).

15 [52].

16 [2015] VCAT 1936.

${ }^{17}$ Ingram, [90].

${ }^{18}$ Ingram, [117].
} 
complying with their obligations under the EOA (Vic) (VEOHRC 2019, 7). The Commission investigated five insurers, which comprise more than $70 \%$ of the travel insurance market, and of the three which still had a blanket mental health exclusion at that time, one did not hold any actuarial or statistical data or provide the VEOHRC with any information to satisfy its reliance on the exclusion, one held sufficient data but the VEOHRC found the data "did not support a sufficient basis" for relying on the exclusion, and the third held an outdated report which the VEOHRC found it was unreasonable for it to rely on (VEOHRC 2019, 10-11).

\section{EQUALITY DATA COLLECTING, SHARING AND REPORTING}

Given that the current enforcement model relies heavily on organisations complying with the law voluntarily, there is a great need for organisations to collect internal data and for the equality agencies to produce guidance material. This section examines the internal information that organisations are required to collect and identifies the gaps. It then considers the equality agency's role as a gatekeeper to information, noting that it only deals with complaints about unlawful behaviour. Thus, at present, the agency is only the gatekeeper to a particular type of information. However, this could be altered, a proposition taken up in the final part of this article.

\subsection{EMPLOYMENT DATA}

The primary data collection and reporting requirements imposed on employers are found in the Workplace Gender Equality Act 2012 (Cth) ('WGE Act'). Private sector employers and higher education providers with 100 or more employees are required to report against 'gender equality indicators' every 12 months. Those indicators are the gender composition of the workforce, gender composition of any governing bodies of the employer, equal pay between men and women and the availability of flexible work arrangements. ${ }^{19}$ The reports are public and must be signed by the organisation's Chief Executive Officer. ${ }^{20}$

Employers have been required to prepare reports about the gender composition of their workplace for decades, yet these reports did little to address gender equality or the gender pay gap. In terms of data collection, the WGE Act is substantial improvement on predecessor legislation under which there was "little capacity to scrutinise [employer's] responses or hold them to achieving any goals" due to a lack of reporting, incomparable datasets and no means of enforcing compliance (Smith and Hayes, 2015, 192). Consequently, the Workplace Gender Equality Agency ('WGEA') has gathered very rich data about the gender composition of individual workplaces and industries, pay, conditions and entitlements. Data can be perused via its online 'data explorer'. The agency uses this data to raise awareness of problematic industries or areas, and to work with employers to make improvements (see further Smith and Hayes 2015; Blackham 2021).

Some public services are under an obligation to collect and report on data but only in the context of employment, not the delivery of public goods and services. Commonwealth public authorities are required to collect data about their employees' gender, Aboriginal or Torres Strait Islander Status, disability and their cultural and linguistic background. ${ }^{21}$ The Australian Public Service Commission is required to collect data about the composition of the Commonwealth public service.22 This is published in its annual State of the Service report. Similarly, the state and territory public services are required to collect data about the composition of their workforce and report on this annually. For example, the NSW Public Service Commissioner is required to report annually on workplace diversity across the public sector. Diversity includes gender, cultural and linguistic background, Aboriginal people and people with a disability. ${ }^{23}$

\footnotetext{
${ }^{19}$ WGE Act ss 3, 13 .

${ }^{20}$ WGE Act s 13.

${ }^{21}$ Equal Employment Opportunity (Commonwealth Authorities) Act 1987 (Cth) ss 3, 5.

${ }^{22}$ Public Service Act 1999 (Cth) s 44.

${ }^{23}$ Government Sector Employment Act 2013 (NSW) s 63.
} 
Since 31 March 2021, Victorian government departments, agencies, universities, and local councils have been subject to audit requirements contained in the Gender Equality Act 2020 (Vic) which requires them to collect "gender-disaggregated data" and report on the state and nature of gender equality in the workplace. ${ }^{24}$ The Act's data collection requirements are very similar to the WGE Act ${ }^{25}$ but it is also concerned with how inequality can be compounded so data about other attributes (such as Aboriginality, disability, religion and race) is to be collected if available. ${ }^{26}$ Again, data collection is limited to the public sector and to gender.

\subsection{DATA COLLECTED BY THE EQUALITY AGENCIES}

The equality agencies are gatekeepers to a wealth of information about how members of the community are experiencing discrimination. In every jurisdiction except Victoria, it is compulsory to lodge a complaint at an equality agency before the claim can be litigated. The agencies' functions include collecting data about discrimination and inequality. This is stated explicitly for the agencies in South Australia, the Northern Territory and Tasmania. ${ }^{27}$

The agencies, therefore, not only hold information about the attributes and areas that people are lodging complaints about, but they also hold information about the nature of that discrimination; how the respondent dealt with the claim; whether it was a one-off; and how the claim was resolved and at what point. They do not gather demographic data via their online complaint lodgement forms but information about the complainant, respondent and the nature of the discriminatory conduct could - and may well be - extracted from the complaint file.

Despite holding such rich information about discrimination, the agencies release very little of this publicly. Annual reporting is largely about financial obligations. Complaint data is limited to data on the attributes and areas upon which complaints were lodged (Allen, Blackham 2019). Indeed, the depth of information they each release about complaints varies drastically. For example, the VEOHRC's most recent annual report does not include any complaint data. By contrast the Australian Human Rights Commission releases a separate Complaint Statistics publication each year.

\section{UTILISING DATA TO INFORM DECISION-MAKING AND IMPROVE EQUALITY}

Not only are there disparities in the depths of information collected and released by the equality agencies, there are large gaps in the information that organisations, both public and private, are required to collect. In terms of private sector organisations, only large employers are covered by the WGE Act and the information they are required to collect and report on is limited to gender. There is no requirement to report on other attributes which result in inequality and disadvantage, such as Aboriginal or Torres Strait Islander status, race, religion, and disability. ${ }^{28}$ Significantly, educational institutions and goods and services providers are not covered by mandatory data collection or reporting requirements other than in their role as an employer.

The significant gap in what data is collected and released is weakening the effectiveness of equality law. Without a full picture of the state of equality, it is very difficult for employers, educators, and other providers to identify issues and comply with the law proactively, whether that is by amending policies, accommodating particular needs, or designing programs to address identified problems. This is particularly so regarding the exceptions permitting special measures. As described above, the special measures exception is one of

\footnotetext{
${ }^{24}$ Section 11(2), (3)(a).

${ }^{25}$ Compare the definition of 'workplace gender equality indicators' in s 3 of the Gender Equality Act to the definition of 'gender equality indicators' in s 3 of the WGE Act.

26 Section 11(3)(b).

${ }^{27}$ EOA (SA) s 11(2)), ADA (NT) s 13(1)(c), ADA(Tas) s 6(i).

${ }^{28}$ See Cummeragunja Housing \& Development Aboriginal Corporation [2011] VCAT 2237, [29] where VCAT referred to data from the Australian Bureau of Statistics about the employment rates, educational qualifications and life expectancy of Indigenous people overall when considering whether the applicant's desire to recruit Indigenous applicants to work in an Aboriginal community.
} 
the only instances in which anti-discrimination laws encourage employers and service providers to identify ongoing inequality and develop a strategy for addressing it. By collecting more data and informing itself about the state of their organisation or the needs of their customers or clients, an organisation would be better placed to develop a targeted approach. For example, as part of the process of applying for an exemption to recruit female academic staff, as well as gathering data about the gender balance of its current staff and students and forecasting these rates, the School of Engineering at the University of Melbourne surveyed staff and research students. In response to feedback, it received that staff and students needed support to develop the careers of women, rather than implementing a quota, the School agreed to incorporate support of that nature. ${ }^{29}$

It is not a complete solution, however, to say that all that needs to be done is for organisations to collect information about the complete range of attributes and areas covered by equality law. Data collection is not enough in and of itself; it needs to be used to inform action. Thus, increased data collection will only be an improvement on the current model if it is accompanied by an obligation to do something if the data reveals a problem. In this regard, a three-stage process is required, as illustrated by Figure 1, for collecting, sharing and utilising the data to address identified equality related issues.

\section{Collect}

\section{Analyse}

\section{Respond}

\section{FIGURE 1}

The first stage does not require further explanation; it is an extension of what many organisations are required to do under the WGE Act. What is proposed is to expand the parameters of what data is currently collected and shared, and by whom. Specifically, organisations should collect de-identified data about race, age, disability, at a minimum (other protected attributes may well be relevant also, depending on the organisation). The type of organisations required to do so should be expanded to include smaller organisations, and educational institutions and providers of goods and services in their capacity as a service provider, not only as an employer. Expanding data collection in this way would give the organisation a broader internal picture and increase the dataset available to the agency responsible for receiving and analysing the data ('the reporting agency').

An organisation will not be able to develop a response to an issue without a good understanding of what they are dealing with. This will require the organisation itself to conduct an internal analysis of its data and to prepare a strategy for addressing any issues. This is part of the WGE Act. The Minister can set gender equality indicators and the WGEA can ask an employer subject to the Act to provide it with information assessing its performance against those indicators. ${ }^{30}$ If it has not met the minimum performance standards, an employer will have to develop a strategy for doing so and avoid becoming a non-compliant employer under the Act. ${ }^{31}$ It is therefore in the interests of employers to act upon the data they collect by benchmarking themselves against the minimum standards and identifying ways to improve if need be. Similarly, under the new Gender Equality Act 2020 in Victoria, organisations are required to complete a workplace gender audit of their workplace each reporting year. Like the WGE Act, organisations must benchmark against gender equality indicators and any targets or quotas prescribed for them based on previous audits. The Act goes beyond the WGE Act requirements in that, organisations are also required to consider additional attributes which may contribute to disadvantage such as Aboriginality, disability, race, and religion when preparing the audit. ${ }^{32}$ The organisation will use this audit to assist with preparing a

\footnotetext{
${ }^{29}$ The University of Melbourne (Melbourne School of Engineering) special measure declaration [2014] VCAT 887.

30 Section 19A.

${ }^{31}$ Section 19C.

${ }^{32}$ Section 11.
} 
Gender Equality Plan which must include strategies for promoting gender equality in the workplace. ${ }^{33}$

As both examples show, the analysis stage is inexorably linked to the third stage because part of analysing the data is responding to what it reveals. For example, an employer might identify an under representation of Indigenous peoples within the organisation or in senior leadership positions and utilise the special measures exception to target Indigenous recruits.

The organisation is not the only entity with a role to play in responding to what the data reveals under the proposal developed in this article. As the repository for all of the data, the reporting agency would have access to the 'big picture' of the state of equality overall, different attributes and areas, and in each industry location. From this, it could identity emerging issues, patterns and systemic problems. This would inform its educative and research roles. Having access to much more detailed and sector specific information would mean the reporting agency is better equipped to work with organisations and target problems early on, rather than once they have spread - back burning to avoid the devastation a fire can cause. The WGEA experience shows how data can be used effectively in this way. Smith and Hayes traced the history of gender equality reporting in Australia and found that the first iterations of such legislation failed to achieve their goals because of problems with disclosing data and the quality of the data that was collected $(2015,196)$. They show that in contrast the WGEA has 'access to an enormous data set about Australian employers' which it has used to prepare reports about, for example, the gender pay gap across various industries and providing reporting employers with an individualised benchmark report (2015, 208-209). Most recently the WGEA said it will use its repository of data as a benchmark for assessing the impact of COVID19 on gender equality (WGEA, 2020). At the time of writing, the first set of Equality Action Plans had yet to be submitted under the Gender Equality Act 2020 (Vic). It is anticipated that the information contained in these Plans will garner a rich dataset of information about the status of women in Victorian workplaces in years to come.

This proposal has resourcing implications for both the reporting agency which will require adequate funds to receive, analyse, use and publicise the data. Smith and Hayes note that the WGEA received almost double the funding of its predecessor because of its increased responsibilities $(2015,208)$. The Victorian government committed $\$ 13$ million in its 2020-21 budget to support the implementation of the Gender Equality Act 2020 (Vic) $(2020,5)$. Moreover, organisations will need time to understand reporting requirements and put in place processes for collecting the data and implementing finds. It is here that the reporting agency's role in providing information about the role obtaining data can play in addressing inequality is crucial and ensuring that organisations have the skills to do this. For example, in the lead up to the commencement of the Gender Equality Act 2020 in Victoria, the agency developed guidance materials, conducted workshops and training sessions, and established a list of preferred specialist consultants to assist organisations to meet their auditing and reporting requirements (https://www.genderequalitycommission.vic.gov.au/support-defined-entities).

\section{CONCLUSION}

The model for equality law is premised on the idea that data and information will be available to inform organisations about how they can tackle discrimination and inequality. As this article shows, very little informative data is available either because organisations are not required or motivated to collect it or what they do collect is not extensive enough. Having access to more comprehensive and targeted data would permit a systematic evaluation of issues as they arise rather than waiting until a discrimination complaint is made. Yet collecting data is not enough in and of itself. The organisation needs to be required to analyse the data and use it as the basis for decision-making. This would imbue more thought into decision-making, rather than an organisation continuing to do what it has always done. Having

\footnotetext{
${ }^{33}$ Sections 10,12
} 
identified a problem, the organisation would be obliged to change its practices, policies and processes so that they do not impact adversely on equality or face the risk of a discrimination claim. The goal of this approach is that organisations do not carry on performing 'business as usual', thus perpetuating inequality. This is what occurred in the Ingram case. A blanket policy was imposed without considering whether it was still appropriate. Instead, organisations should be encouraged and supported to collect information and review their status as a workplace and/or goods and services provider particularly as the nature of society changes and new forms of inequality emerge and others reduce. The approach put forward in this article would mean organisations would be better equipped to respond to change with evolving policies and practices.

\section{REFERENCES}

1. Allen, D. 2009. "Behind the Conciliation Doors Settling Discrimination Complaints in Victoria" 18(3) Griffith Law Review 778-779.

2. Allen, D. 2016."Barking and Biting - the Equal Opportunity Commission as an Enforcement Agency" 44(2) Federal Law Review 311-335.

3. Allen, D., and Blackham, A. 2019. "Under Wraps: Secrecy, Confidentiality and the Enforcement of Equality Law in Australia and the United Kingdom" 43(2) Melbourne University Law Review $385-422$.

4. Blackham, A. 2021."Positive Equality Duties: The Future of Equality and Transparency?" 37(2) Law in Context OnLine First.

5. Nguyen, K. .2020. "The QR code has turned COVID-19 check-ins into a golden opportunity for marketing and data companies" ABC News, 2 November.

6. Smith, B. 2006. "Not the Baby and the Bathwater: Regulatory Reform for Equality Laws to Address Work-Family Conflict" 28 Sydney Law Review 689-732.

7. Smith, B., and Hayes, M., 2015. "Using data to drive gender equality in employment: More power to the people?" 28 Australian Journal of Labour Law 191-213.

8. Thornton, M and Luker, T. 2010."The New Racism in Employment Discrimination: Tales from the Global Economy" 32(1) Sydney Law Review 1-27.

9. Victorian Equal Opportunity and Human Rights Commission 2019, Fair Minded Cover.

10. Victorian State Government (2020), Victorian Budget 2020/21 Gender Equality Budget Statement.

11. Workplace Gender Equality Agency "New WGEA data shows employer action on gender equality has stalled"26/11/2020.

\section{Legislation}

1. Anti-Discrimination Act 1977 (NSW)

2. Anti-Discrimination Act 1991 (ACT)

3. Anti-Discrimination Act 1991 (Qld)

4. Anti-Discrimination Act 1992 (NT)

5. Anti-Discrimination Act 1998 (Tas)

6. Australian Human Rights Commission Act 1986 (Cth)

7. Disability Discrimination Act 1992 (Cth)

8. Equal Employment Opportunity (Commonwealth Authorities) Act 1987 (Cth)

9. Equal Opportunity Act 1984 (SA)

10. Equal Opportunity Act 1984 (WA)

11. Equal Opportunity Act 2010 (Vic)

12. Gender Equality Act 2020 (Vic)

13. Government Sector Employment Act 2013 (NSW)

14. Public Service Act 1999 (Cth)

15. Sex Discrimination Act 1984 (Cth)

16. Workplace Gender Equality Act 2012 (Cth)

\section{Case law}

1. Waite Group [2016] VCAT 1258

2. Ingram $v$ QBE Insurance (Australia) Ltd [2015] VCAT 1936

3. QBE Travel Insurance v Bassanelli [2004] FCA 396

4. Auto \& General Insurance Company Limited v President, Anti-Discrimination Board [2010] NSWADT 229 